\title{
Multilingual Content in Teaching the Kazakh Language Courses
}

\author{
By Elmira Orazaliyeva ${ }^{*}$ \& Fauziya Orazbayeva ${ }^{ \pm}$
}

\begin{abstract}
According to the second state program on the development and functioning of languages until 2020, Kazakhstan concentrates on consolidating the Kazakh language as the state language, where Russian, English or others are foreign languages. New educational programs of the country assume a step-by-step implementation of communicative language skills. Students receive a possibility of relaying certain knowledge in the field of natural, human and technical sciences. The mission of Abai Kazakh National Pedagogical University as the educational center of transforming the results of advanced research in the field of pedagogy, teaching methods are implemented to prepare teachers in order to support multilingual content approaches in education. It is expected that in high schools four natural subjects like chemistry, biology, computer science, and physics will be taught in English, Kazakh, and Russian, while history, language, literature and other art sciences will be the subjects of the Kazakh or Russian languages. The school programs with general educational standards are aimed at creating a base of modernly demanded and replenished knowledge. It explains the creation of the International Nazarbayev University which is unique in Kazakhstan. High admission requirements characterize selection quality, and targets in mastering foreign languages.
\end{abstract}

Keywords: multi-academic content, multilingualism, cross-cultural expertises, educational methods and strategies, educational approaches

\section{Introduction}

Nowadays, academic multilingual content for the Kazakhstani education system is important. Notoriously, the country now finalizes the last decade of the second State Program and systematizes the indicators of developing and using languages. The main idea of the Program is to save languages of all ethnic groups in Kazakhstan, and to increase the role of the Kazakh state language as a factor of solidarity. Language policy provides wider uses of three or more languages justifiably by encouraging the delineation of their social role. ${ }^{1}$ As a result, educational content combines different language sources. The methodology of the learning process, including motivation, needs be analyzed and therefore content materials may be afforded by new approaches. The vocabulary of the Kazakh language is also in the process of developing and systematizing new concepts and resources. In this case, Russian and English languages are the key acquisition

\footnotetext{
*Associate Professor, Nazarbayev University, Kazakhstan.

${ }^{ \pm}$Corresponding Member of the Republic of Kazakhstan's National Academy of Sciences and Professor, Abai Kazakh National Pedagogical University, Kazakhstan.

${ }^{1}$ The standards for studying the Kazakh language were prepared in 2014 by the Ministry of Education and Sciences of the Republic of Kazakhstan.
} 
zones. Therefore, among other significant characteristics, quantitative data of people who know and can use foreign languages are in the process of preparing the analysis. It means a percentage ratio of citizens with three lingual abilities has its own calculation. These options show that Kazakhstan today has a vital language policy with ubiquitous dissemination.

For Kazakhstan, multilingual education is the topic of explicit and clear needs within essential applications. Based on the evidence cited in the daily lifestyle of citizens, it would seem logical to assume that people, especially the younger generation, use more than three languages for educational and communicative goals. Multilingualism is supported by the state and new institutional programs as a part of crucial economic, political, and social positions worldwide. Firstly, Kazakhstan highlighted the significant role of the Kazakh language by legal, vested and viable comprehensions, and secondly took into account the important impacts of both Russian and English languages. Thirdly, as a country with more than 130 ethnic groups, it promotes and maintains reviving policy of minority languages in the Republic. The dignity and aspiration to perpetuate their roots as a heritage and strength have become long, drawn-out templates. Thereupon, motivation is remarkably valuable and a required element of any educational procedure which increases people's capacity for the reinvention of their targets and views. The logical sequence of this assumption is that today, Kazakhstan simultaneously intends to create an intelligent society to save its national and cultural identity.

In the future it is expected that four natural subjects will be taught in parallel in English; this list includes chemistry, biology, computer science, and physics. Alternatively, history, language, literature and other art sciences will be the subjects of the Kazakh and Russian languages. Today, this form of knowledge transition is used by Kazakh-Turkish, Nazarbayev Intellectual, and Daryn (which means "talent" in the Kazakh language) schools. As officially mentioned in 2015, there were 33 schools with three language instructions in operation. In the same year, 18 Nazarbayev Intellectual Schools' teaching was conducted in English, including the passing of international external exams. Also, in 30 Kazakh-Turkish lyceums, individual subjects of the natural-mathematical cycle were taught in English. For that reason, in 2012, at 42 universities and institutes, English groups were additionally started and enlisted below: 17 groups in Abai Kazakh National Pedagogical University; 19 groups in Taraz State Pedagogical Institute; 57 groups in Pavlodar State Pedagogical Institute; and 19 groups in South Kazakhstan State Pedagogical Institute. Nowadays, 18,006 people are studying in 2,393 groups. Among them are 16121 undergraduate students, 1,662 masters, and $223 \mathrm{Ph} . \mathrm{D}$. students. The pedagogy has its separate calculation in detail - the undergraduate level consists of 4581 students, the master's degree includes 153 and Ph.D. 15 students. There are 4,749 students, 1,710 of which are specialized in physics, chemistry, biology, computer science, and history. Each year, about 427 graduates receive diplomas. According to Muhamediev (2017), in 2008 7,983 people graduated with three lingual specialties; $58.5 \%$ of them have a stable operation and consists of 4,690 people.

In a gradual and stepwise manner, Kazakhstan tried to accomplish and 
distribute the applicability of new language teaching methods and strategies in education. Therefore, the Roadmap's analytical introduction of the current situation in Kazakhstan in 2014-2015 showed that 111 trilingual groups were created in 7 pedagogical academies. ${ }^{2}$ The nominative faculty who speaks Russian, Kazakh, and English has been appointed. Students of all specialties study the disciplines "Professional Kazakh (Russian) language" and "Professional foreign language". The level system of language teaching has been introduced according to the international standards. Persons who have a certificate of passing a foreign language in special programs are exempt from the entrance examination in a foreign language in the Master's, Post-graduate and Ph.D. programs. Students and undergraduates under the academic mobility program are studying in the countries participating in the Bologna Process, which are countries of the European Union and the USA. Foreign scientists and teachers have been involved (Roadmap for the development of trilingual education for 2015-2020 2015). ${ }^{2}$

As a logical sequence, in the article the outcomes of multi-academic content are described by communicative, cross-cultural and cognitive impacts in a society. According to the article of Nursultan Nazarbayev, ${ }^{3}$ today, "the preservation of national culture and tradition" needs to work as "a platform of past, present and future connections" of spiritual modernization including competitiveness, pragmatism, preserving national identity, open attitude, and evolutional development. It means "being open to the best practices and experiences of other people and countries," to have a dialog and to be successful, where history and national traditions must be taken into account. Thus, the expected social and economic impacts of this article can be calculated by the conception that the model of cross-language academic content education in Kazakhstan based on the principles of communicative-cognitive, socio-mental and intellectual aspects combines the processes of co-study of sociolinguistic and cultural features in the interaction of historical and global factors.

\section{Literature Review}

Currently, the desire to talk and understand without a translator, and to be a highly intellectual person with a wide world outlook is a dream of most people. Most significantly, it is the goal to be productive and communicative in business relations; the conception that bilinguals use their languages for different purposes, in different domains of life, to accomplish different things. Their level of fluency in a language depends on their need for that language.

\footnotetext{
${ }^{2}$ The Roadmap for the development of trilingual education for 2015-2020 was prepared in 2015.

${ }^{3}$ The national program of Nursultan Nazarbayev "Course towards the future: modernization of Kazakhstan's identity” was published in April of 2017.
} 
Hence, many bilinguals are more fluent in a given language, and some cannot read or write one of their languages, which is investigated by Grosjean and $\mathrm{Li}$ (2013, p. 7), which justifies the main points of scholars' discussions about psychological, cognitive and social issues of multilingual capacities. "Different aspects of life often require different languages (Grosjean and Li 2013, p. 12)," and also reproduce different emotions and feelings. As a consequence, it is necessary to clarify in the educational system setting the basic roles of multilingual cognition, multilingual psychology, and multilingual competences.

Arguably, as mentioned by Baklovskaya (2015, p. 4), "multilingual students have to obtain cross-cultural communicative subsistence." Among them, the scholar expands lingua-cultural, cognitive, educational strategic, behavior competences as the tools of social and cultural inclusion, which can be made possible by teaching foreign languages and developing multilingual content. In this case, the cross-cultural experiences and needs become the objectives of diagnostic approaches with "the content cooperation between a teacher and student" and the creation of a conceptual stage of cross-cultural technology. Therefore, for example, the Institute of Foreign Languages and Literature of Udmurt State University and Abai Kazakh National Pedagogical University have a practice of teaching the specialty "Multilingual Education". Multilingual skills can develop students' social and professional subsistence by comparative analytical opportunities. Thus, cultural heritage and geography of languages distribute new skills and create the conception of Baklovskaya's special "language personality" characteristics (Baklovskaya 2015, p. 5). This also means that multilingual content has an equal interpretation of additional merits and definable measures of cultural, mental, cognitive, and intellectual transitions. The presence of language diversity incorporates plenty of transitive comprehensions and goals, because, “... it is important to note that language dominance in a bilingual can change over time. Thus, a person's first language may not always be his or her authoritative language." 5

Edwards (2012, p. 176) explained that, "the existence of many languages in the world implies the existence of many cultures. It is the interrelationships among languages and their speakers which create interest and tension." For that reason, any high intellectual person has the opportunity to feel cross-cultural intentions and to reveal the grain of crucial decisions. It is well recognized that a person with wide world outcomes can develop "personal characteristics such as diligence, determination, motivation, discipline, activity, initiative in finding own methods of learning languages." Additionally, a person's multilingual preparation opens the

\footnotetext{
${ }^{4}$ Wide academic content needs good multilingual basis in positions of personal language history and life description or social recognition and education (Grosjean 1982, Grosjean and Li 2013, Edwards 2012, Lopareva 2015, O’Malley and Chamot 1990, Oxford 1990, Allwright 1990), differences and similarities with types classifications (Weinreich 1974, Appel and Muysken 1987), impacts of Multilingualism on education, communication in society (King and Carson 2016, King 2018, Bogenbayeva et al. 2017, Orazaliyeva 2019) and cognitive benefits or negative effects (Palinkašević and Palov 2014, Viorica and Shook 2012).

${ }^{5}$ It goes to show, that "Personal language history may show quite different bilingual configurations at different moments in time" (Grosjean and Li 2013, p. 13).
} 
"quality of the synthesis of tolerance, empathy, and re-evaluation" (Baklovskaya 2015 , p. 14). This assertion might assist in the general understandings of multilingual education, which involves "the physiology of bilinguals and their interests (due to age)." By the Kudryavtseva (2015, p. 29), differences begin in the field of self-perception and attitude. Meanwhile, multilingual content as a model of important and valuable capabilities shows that, "Beyond an individual level at which multilingualism and multiculturalism might overlap, it is also clear that social recognition - perhaps at a policy level - of one involves the other, too" (Edwards 2012, p. 175).

Normally, these species can be results of extra-lingual factors, as mentioned, "the features of the worldview and self-awareness of bilinguals described above stem from the life situation that gave rise to their natural multilingualism." Furthermore, it is important to make a distinction between learning languages, cultures, and select their content as a "mutual integrative safety triangle" by Kudryavtseva (2015, p. 30). It includes, firstly, "family education and upbringing"; secondly, "regular education: school, university"; and thirdly, "additional and selfeducation". It means, language education is the subject of intellectual, pedagogical and psychological sciences and teaching along learning methods indicate an important part of content analysis. ${ }^{6}$

\section{Methodology}

Notoriously, Edwards (2012, p. 193) stated: "in bilingual education, teaching through two languages is a permanent feature in the classroom. Again, this can arise for non-instrumental reasons, as part of educational philosophy; more commonly, though, bilingual education is driven by need." For that reason, needs identification is one of the most significant instruments of outlining the goals of new educational procedures. Among them, Lopareva (2015, p. 42) combines the next types of teaching methods: "smart guessing", hypothesis testing, new knowledge integration into existing, parallel use of various sources of information and materials, application of words of the native and learned foreign languages, perception and use of related languages, application of metalanguage terminology," and so on. Oxford (1990, pp. 37-55) indicates two main groups: direct and indirect foreign language learning methods. The first group includes mnemonic (memoryrelated) strategies, cognitive strategies, compensatory strategies, the second metacognitive strategies, affective learning strategies, social strategies. O'Malley and Chamot (1990, pp. 137-138) highlighted the types of cognitive, metacognitive and socio-affective strategic methods. The first benefit of using these approaches

\footnotetext{
${ }^{6}$ In that case, learning methods and strategies are "specific actions, behaviors, steps, or techniques such as seeking out conversation partners, or giving oneself encouragement to tackle a difficult language task - used by students to enhance their own learning" (Scarcella and Oxford 1992, p. 63). Methods considered effective when the targets are completed and the learning process has necessary and positive outcomes for the next step of life-long (Allwright 1990, Little 1991) education. For example, the learning strategy description includes two basic concepts - plans or methods, and educational achievements (Ubedh 2016, p. 5).
} 
is the ability to improve cross-cultural opportunities to develop cognitive and communicative competences. The second one is concentrated on the refining of individual skills during analyzing or thinking procedures. The next comprehension is based on the increasing of cognitive perceptions as "creating of associative lexical basis," by Baklovskaya (2015, p. 6). Lebedinsky and Herbik (2011, pp. 118-119) engaged the classification of foreign language acquisition strategies and foreign language strategies (which means using).

In this article, teaching Kazakh language courses expand by multilingual and academic content interaction. Moreover, outputs of using multilingual contents are analyzed by two conditions: for students with the Kazakh language as a second, and for students with the Kazakh language as a first or native. Based on the pedagogy results, the interesting effects of multilingual skills on the course or discipline outcomes can be identified. It is important to present the influence of cognitive, communicative and social targets to study and use languages. It is true that the Kazakh language courses have common and different commitments or motivations.

According to the theory of Litosseliti (2010), it is necessary to distinguish the main descriptive, explanatory and evaluative research questions for analysis. In our case, this underlined our next questions: "Does multilingual education create high intellectual potential?"; "Does multilingual education form deep cognition?"; and, "Should multilingual education impacts to the cultural values of the individual?" The Kazakh language in the position of a second language focuses on students' needs to communicate, to talk and to use it for special purposes. In fact, these functions are underpinned by the opportunity for the students to read, write, listen and speak. Students try to learn another language with the help of the first one. As a result, comparative explanations and additional mother tongue materials are helpful. Intrinsically, multilingual skills can create special abilities of the educational platform. For example, Baklovskaya (2015, pp. 6-7) analyzed "speech abilities (phonemic hearing, the ability to simulate sounds and intonation, a sense of language, etc.); mental functions associated with speech activity (memory in all its forms, attention, imagination, etc.); willingness to communicate in foreign languages (openness, emotionality, sociability, empathy, etc.); motivation for independent study of foreign languages and cultures (acquiring a positive attitude towards them); willingness to form their own learning strategies." This means that multimethod studies, along with descriptive and comparative methods with deductive and inductive approaches, are useful in clarifying the role of content analysis in language teaching or learning environments.

Studying the Kazakh language as foreign includes the elements of the crosscultural, geographical, ethnic excursion, and stimulates students' creativity in cognition and communication. Carlile and Jordan (2012, p. 2) investigated the meaning of the word creativity as, "the new and unpredictable, while the overall aim of education is to develop predictable, learned behaviors for future application.” In fact, Boden (1994) defined creativity as, "a conceptual ability to come up with new ideas that are surprising, yet intelligible and also valuable," or it can be an "effective surprise" (Bruner 1979). The integrated teaching system of the Kazakh language as a second language consists of the main conception, 
language standards, typical program, textbooks and methodological complex, which includes a teacher's textbook, workbook, lexical minimum and didactic materials. The desire to reveal something new starts with the topics of the educational programs at schools. Consequently, each step of the continuous or lifelong education (kinder garden, schools, gymnasiums, special professional-oriented colleges, higher education institutions and Academy of Public administrations), is enhanced by the synergy of ontogenetic and methodical approaches with nominative, cognitive, communicative, structural and social texts, and be the subject of conversation or critical discourse analyses (CA or CDA).

\section{Data Analysis}

It might be interesting to pay attention to the conceptions at each level. They create the mental root of the Kazakh language and valuable heritage content for non-Kazakh people, or for people who have limited background in the Kazakh language and history. For example, the method of using the Kazakh words as a topic or textbook name form the cognitive basis through summarizing and outlining activities. The program of the Kazakh language as a second language at a primary school called "Tilashar"7 suggests the first steps in mastering the language for children in grades 1-4. At the higher level (grades 5-7), the program is called "Boytumar." The main idea at this stage is focused on the teacher's desire to discover the internal capabilities of the Kazakh language, generating interests not only to the language structure, but also respect for its speakers by perceiving its culture and traditions. For classes 8 and 9 at the Pre-Intermediate level, the "Til Orda" program has been prepared. The cognitive prerequisites of the course suggest using the language as an instrument of internal harmony, as a fortress of consciousness and readiness for social integration. The intermediate level in grades 10-11 is taught according to the "Aldaspan" the opportunity to improve their communicative and cognitive skills in the Kazakh language by delving into the process of socialization and cultural adaptation deeper and quicker. New words with parallel native explanations motivate learners and help them in cultural discourse searches. Also, different pictures and cognitive texts orient them to a new level of communication in a society. This curriculum was prepared by teachers of the Abai National Pedagogical University. The main concept is based on the ideas of the famous Kazakh scholar Khalil Dosmukhamedov: "Only the language of schools can become the language of the government." In the 2015-2016 academic year, this complex was tested by 41 schools of Kazakhstan, among them are schools №31, №53 from Astana (now Nur-Sultan), school №52 from Almaty. In 2016-2017, 67 textbooks were published for school students (grades 1 to 11). In 2016, the East Kazakhstan region conducted a separate experiment by launching the use of these textbooks in all

\footnotetext{
${ }^{7}$ In literal translation this means "discovering the language".

${ }^{8}$ In the Kazakh language it means an amulet, a talisman.

9The translation is "language is the fortress".

${ }^{10}$ The program means elevation or skyscraper.
} 
schools. Today, the complex is testing this in China to learn Kazakh as a second or third foreign language. One of the main priorities today is to understand that any second language with useful content unlocks additional abilities to value, to design, to promote, to consume new cognitive and useful knowledge. The problem is actualized by the desires of people to perceive, to acquire and to evaluate. Cultural symbiosis and multilingual hybridity, intrinsically, create the acquisition of intellectual capital with a meaningful comprehension of social values.

At the beginning of the twentieth century, the famous Kazakh scientist Zhusipbek Aymauytov asked in his article, "How we can teach the mother tongue?" and noted that, "training should be based not from textbooks to life, but from life to textbooks" (Aymauytov 2016). Therefore, one of the main points of any curriculum is to be useful in content and concepts. Most significantly, multilingual approaches equally collaborate with multicultural and multidisciplinary facts. Perfect segmentation justifiably combines cross-cultural content and illustrates examples of historical and modern life situations. The cognitive core of these materials aligns plenty of life scenarios, concepts, and perceptions, which argue the integration nature of language sciences with philosophy, psychology, cultural studies, anthropology, political or economic knowledge. The question, "What should a multicultural program look like at school?" has two points of explanations by Edwards (2012, pp. 188-189): "one, now almost entirely rejected at an intellectual level but still much in evidence, is a sort of ethnic show-and-tell in which cultural manifestations are paraded in a self-conscious and often trivial fashion. The second approach involves a broader and less superficial stance on multiculturalism." For teaching the Kazakh language courses, it is important today to clarify and identify cultural, cross-cultural and academic content minimum cognition. It goes to show, firstly, how such universal human mechanisms as memory, imagination, attention work; and secondly, how knowledge is replenished with the help of the intellectual and emotional activity of the brain. Orazbaeva (2019, p. 179) emphasizes that cognitive goals in the process of teaching the Kazakh language are based on tasks that enable students to understand the national canons of the Kazakh people. The implementation of this direction in the methodology of teaching the Kazakh language coordinated by three aspects: 1) by cognitive texts; 2) through special sections, for example, "It is valuable to know ..."; "Let's teach ..."; "Speak correctly"; 3) by using situational tasks or cases that improve speaking skills.

The next analytical step is about using multilingual teaching content at Nazarbayev University (NU). As an English-medium university, it can show prominent results and vital career benefits. As it is known, the bilingual issues of using the Kazakh and Russian languages were the subjects of psychological, social and linguistic research. Nowadays, multilingualism, with its explicit consequences, also stimulates scholars to search the contestable issues of language contacts, interferences, intercalation, and code-switching. Using more than one language requires their systematizing in the mind, and language transitions essentially need to save language ecology. Language as a perception of cultural diversity and identity maintains the crucial core of valuable heritage. Here, multilingualism will conceive in a transferable knowledge embedded by subject-based (for example 
STEM/ STEAM) content, and language-integrated learning (CLIL) courses. The argument of Edwards (2012, p. 189), he states, is that, "the context already exists in the subject-based curriculum," and is confirmed by the significant sweeping circumstances of elective courses for native speakers. The relevant grain of this cognitive strategy will be the students' mental uniqueness, their capacity to combine Russian, English, Turkish materials and to distribute them to the Kazakh informative content analysis.

Subject-based, or CLIL Kazakh language courses at NU, orient to realize necessary conditions of Oxford's $(1990$, p. 8) language learning strategies as, "to make learning easier, faster, more enjoyable, more self-directed, more effective, and more transferable to new situations." The goal is to promote the development of multilingual intelligence with the preservation of national-cultural roots. The student's interest in multi-vector analysis with the support of various language sources is explained by the desire to deepen the nature of a particular phenomenon, and to understand the prerequisites of formation and features of development. This approach in language education is argued by several results: firstly, conceptual language parallels and inter-language synonyms formed with the help of synchronization; secondly, critical thinking skills and independent ideas are improved; thirdly, with a correct comparison, the features of each language are systematically structured, and linguistic explanation is given to the Kazakh language. In fact, Wulff and Ellis (2018, p. 38) stated that, "learning a language involves the learning of constructions. ... form-function mappings ... conventionalized as ways to express meanings in a speech community."

Socio-affective learning strategies include interpersonal relations of students and describe their emotional involvement in the learning process. According to Baklovskaya (2015, p. 45), they are associated with a learning algorithm of teachers' actions and students' capabilities and psychological characteristics. For that reason, teaching materials expanded by using technical tools such as films and television programs with subtitles, internet, radio, video, phone, video conferencing, voice chat, etc. In our case, students have equal opportunities to match different language materials, to cite different sources, to give examples from various scientific, journalistic or fictional literature (depending on target indicators), to refer to statistical data and the results of sociological studies, while observing only one rule-requirement: the materials must be processed and translated into the Kazakh language. The principle of Oxford's (2003, p. 12) reorganizing information to develop stronger schemas (knowledge structures) is working. As a consequence, students try to calculate many interesting facts and arguments and prepare SWOT or XYZ analyses, to draw conclusions, to give feedback to each other and to summarize. Statistics, interesting facts, and official sources not only enrich the linguistic personality as an intellectual, but also give him/her the opportunity for independent and versatile communication.

During the spring semester of the 2020 year were held the sociolinguistic searches. The goal was to understand the role and destination or mission of multilingual content in the youth life environment and educational targets. The research for comparative analysis focused on the students of two universities: Nazarbayev University (NU) and the Eurasian National University named after L. 
N. Gumilyov (ENU). There were $50 \mathrm{NU}$ students with complete English-medium competencies including different specialties such as engineers, biologists, chemists, mathematicians, specialists in computer sciences, economics, international relations, and politics. Students of ENU at the undergraduate (16 people) and graduate (10 people) levels were represented in the specialty Kazakh language and Literature (5B011700 \& 6M011700). ${ }^{11}$ For analysis, the following questions were proposed: your specialty; level of the Kazakh language; what other languages do you know; does multilingualism or multilingual knowledge help you in your life; how do you use multilingual skills in the lessons of the Kazakh language; what priorities do you notice in the educational process; do you have a desire for additional foreign languages; your purpose of studying.

According to the results of questionnaire, the Kazakhstan's young generation has high interest in foreign languages. In addition, students are speakers of more than two languages. According to the Diagram 1, Russian language speakers are $96 \%$, or 73 students (50 from NU \& 23 from ENU). The percentage of English language speakers is $81.6 \%$, meaning 62 students (50 from NU \& 12 from ENU); students with Turkish language are $18.4 \%$, they are 14 students ( $8 \mathrm{NU} \& 6 \mathrm{ENU})$. The percentage of students with whom speak French is 6.6\% (5 NU students); Arabic 4\%, or 3 students (1 NU \& 2 ENU); Chinese 5\% (4 students: 3 NU \& 1 ENU); German 5\% (4 NU students), Uzbek 1.3\% (1 ENU student), Mongolian $1.3 \%$ (1 ENU student) (Figure 1).

Figure 1. Using and Studying Foreign Languages in Kazakhstan

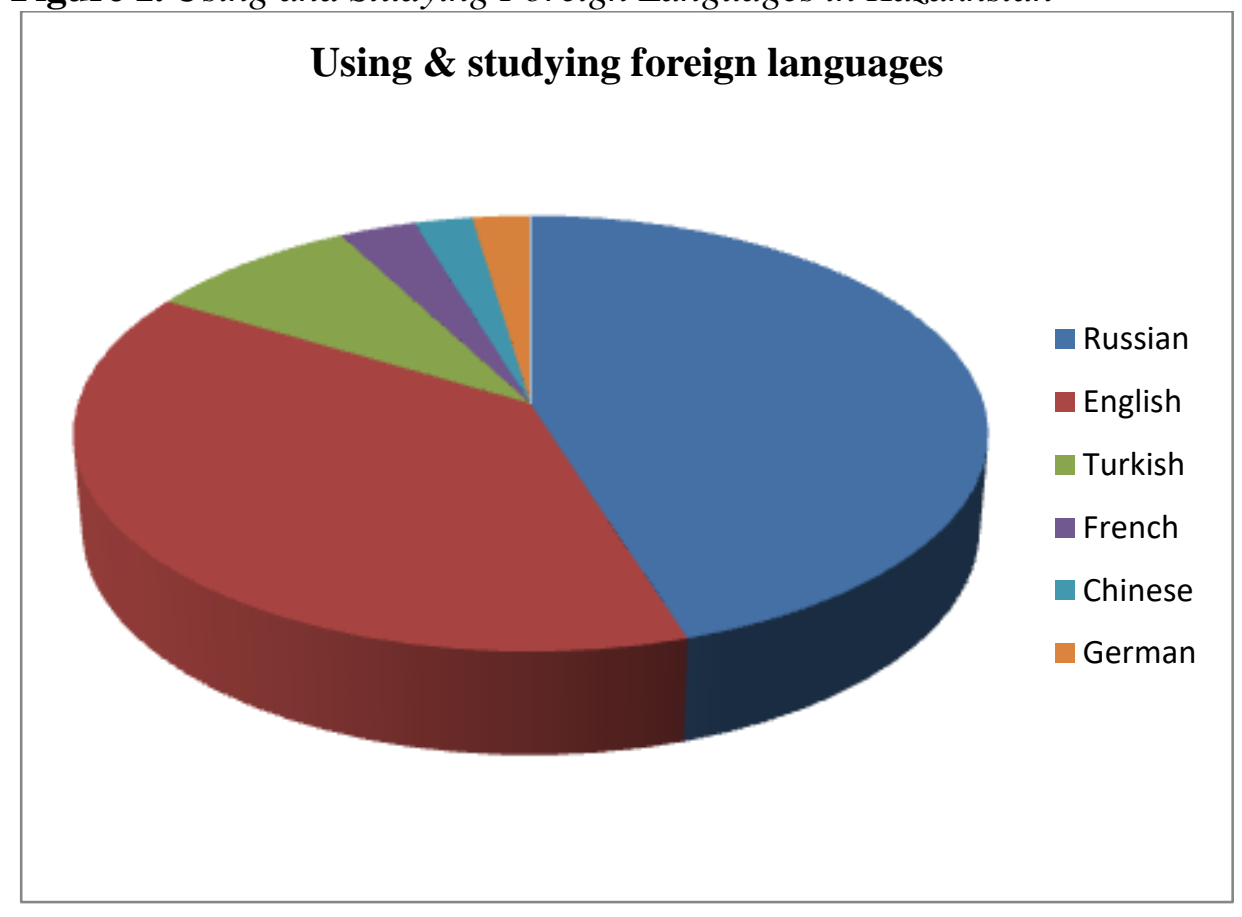

\footnotetext{
${ }^{11}$ Common integrating feature of the participants was their good level at the Kazakh language. The differences included the specialty and areas of using the Kazakh and other languages.
} 
Secondly, most of them stated that they plan to increase the number of foreign languages they study, and often these are the languages of the countries with which they associate certain targets. For example, English, French, German, Korean, Spanish, Turkish, Arabic, Italian, Chinese, Persian and Japanese languages were specifically noted. In this series, priority is given to French, the percentage of which was $18 \%$ (14 students); to English (in this position are the 13 students of ENU, it is 17\%); Turkish - 13\%; German - 11\%; Chinese - 9\%; and Spanish $8 \%$ (Figure 2).

Figure 2. Plans to Study the Foreign Languages in Kazakhstan

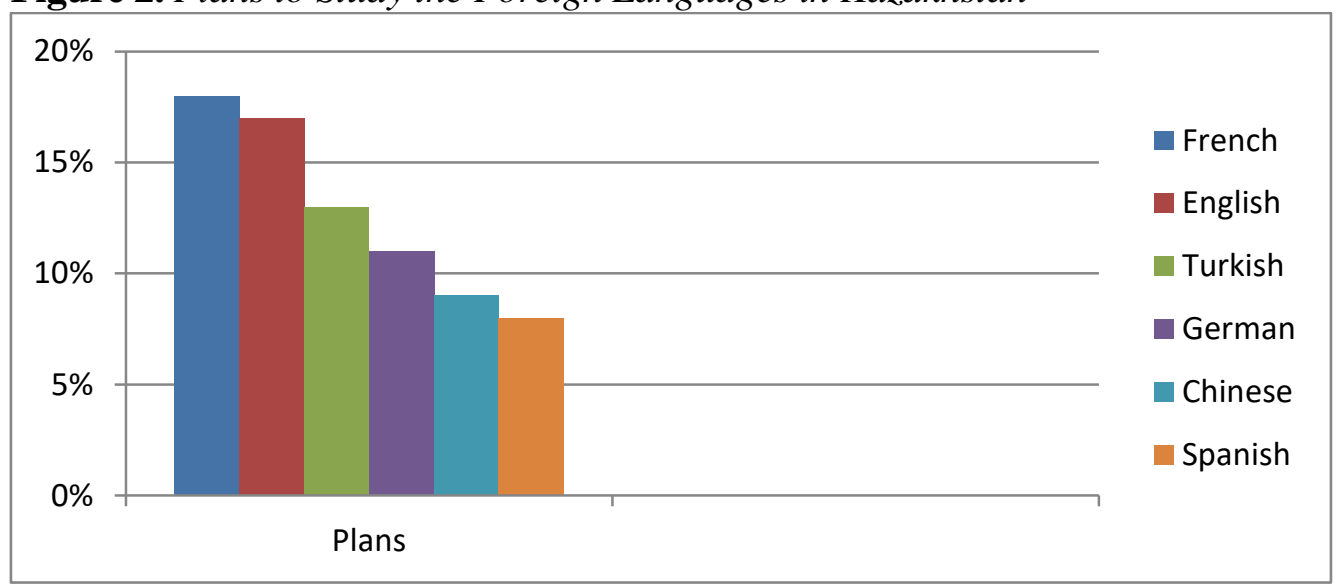

Thirdly, the following positions determined the list of the main target indicators: future work (21\%), future place of study (16\%), travel $(8 \%)$ and personal interest (8\%). In isolated cases, the reasons for personal development, the possibility of exchange of experience, career, time requirement, and familiarity with the culture of other ethnic groups were indicated (Figure 3 ).

Figure 3. Targets to Study the Foreign Languages in Kazakhstan

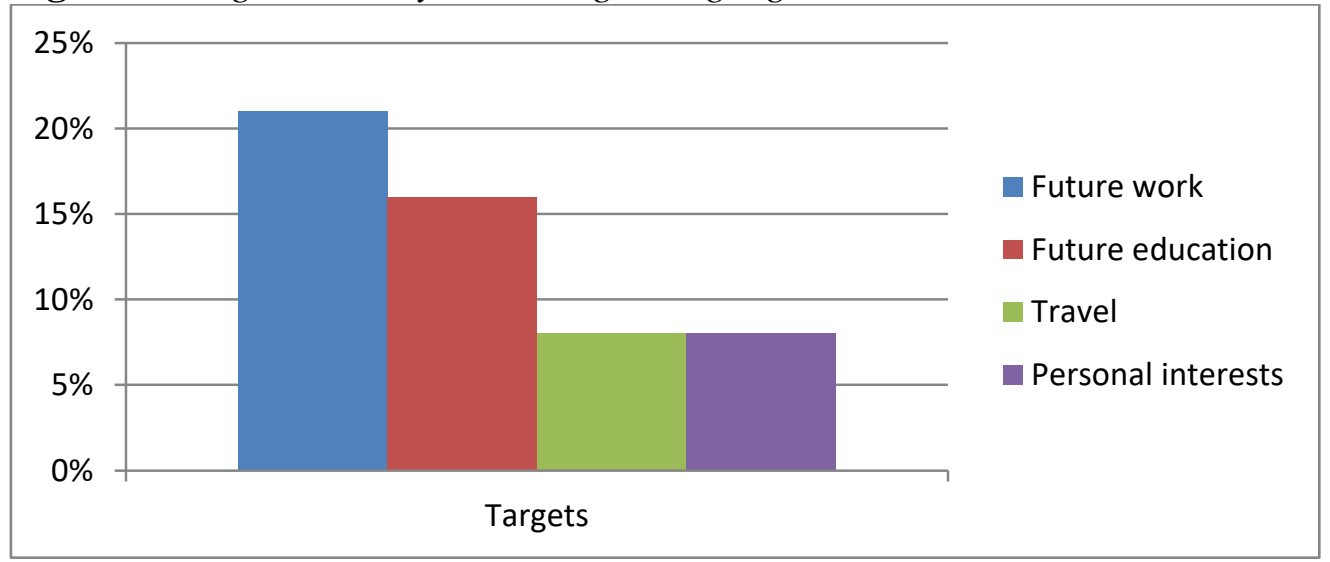

It was very interesting to clarify the role of multilingualism across the Kazakh language courses as a first language. Most significantly, it is necessary to understand the missions of the Kazakh language in two universities: at NU, 300or 400-level courses have CLIL oriented purposes for native speakers and the 
Kazakh school backgrounders. Here, the Kazakh language is compulsory and has a content connection with specialties, like professional Kazakh for Engineers, Kazakh for Medicine, Kazakh for Business, and Kazakh for Civil Service and so on. Also, NU courses align heritage and cognitive knowledge of Kazakh history, literature and culture. In this case, teachers of the Kazakh language create a harmonious union of social needs, scientifically and practically developing language-based communication skills in writing, speaking, reading and listening. As a result, the core of interdisciplinary conceptual relations with the linguisticpedagogical approaches formed. Subject-based orientation and scientific consequences argue the importance of using multilingual content materials. It justifies the list of goals, which is mentioned by NU students. Among them, the following positions can be emphasized: collecting additional material; using Internet resources; the possibility of comparative analysis; forming an objective approach to the problem; a cumulative approach to the knowledge fund; working with the terminology; expanding the conceptual block; working with sources; and the possibility of expanding specialized literature.

The academic content of the Kazakh language courses involves multidimensional, scientific approaches to the theoretical excursion, also applying experience. Nevertheless, the working language of information transfer, discussion, and debate is in the Kazakh language. Therefore, the students become not only a carrier of multilingual information, but also a translator and processor of academic text materials. This form of synchronous or sequential adaptation of scientific materials requires students' language skills and structural knowledge, and, also thorough work on the conceptual content and vocabulary. As a consequence, $82 \%$ of students of NU totally agree that it is necessary to develop the content analysis of the Kazakh language materials across multilingual factors and arguments. In addition, $18 \%$ of students with answers - "no" (3 students), "sometimes" (4 students), "did not think" (2 students) - can show that multilingual comprehension not a mandatory obligation.

The situation at ENU is another. The questionnaire results prove that for the Kazakh-medium environment, multilingualism is not so important, but not excluded. As representatives of the specialty with the Kazakh-medium students' answers have more unofficial and personal characteristics. Therefore, the number of explanations follows from their communicative or cognitive desires to discuss, to talk, to understand, to read, to watch TV. Nevertheless, as a requirement of the time, multilingualism is considered as an integral component of the modern educational process. In this regard, the answers indicate such target indicators as academic mobility, education abroad, participation in international conferences, scientific and experimental expeditions, a publication of scientific papers, exchanges of experiences. The second feature is combined by the specialization of the Kazakh language and literature, which involves a comparative historical analysis of Turkic languages with their structural or semantic analysis. The logical sequence of this statement is the list the Turkic languages as a foreign. 


\section{Conclusion}

Nowadays, according to Palinkašević and Palov (2014), multilingualism with its beneficial and negative effects has debatable outcomes. However, cultural symbiosis and multilingual hybridity, intrinsically, create the acquisition of intellectual capital with a meaningful comprehension of cross-cultural and social values. As an attribute of deep cognitive and communicative activities, multilingualism and multilingual content strategies can unify different educational targets, which was tested through students' feedback and course evaluations. Intrinsically, the reinvention of multilingual capacities is compensated by the opportunity to widely reveal and expand, to equitably compare and amply emphasize. In our case, educational procedures find productive decisions in scientific course projects, parallel readings, searching scientific conceptions, and terminology. Students achieve results with possibility and desire to describe the Kazakh language's academic materials in useful comparison with English, Russian and Turkish languages. The ability to generate and gather information create a self-sufficient intellectual system of education and provide students a significant overview. It is important to make a transitive balance between first and second or third languages as the vital comprehension of cultural and intercultural values. As was mentioned by Palinkašević and Palov (2014, pp. 83-84), multilingualism as bilingualism develops the following cognitive advantages: better ability in reconstructing perceptual situations; greater sensitivity to semantic relations between words; Torrance's greater originality in creative thinking; and the conception of greater metalinguistic ability. Therefore, multilingual education through different languages combines the main learning and teaching strategies of content analysis and informative understandings.

\section{References}

Allwright D (1990) Autonomy in language pedagogy. CRILE Working Paper 6. UK: Centre for Research in Education, University of Lancaster.

Appel R, Muysken P (1987) Language contact and bilingualism. London: Edward Arnold.

Aymauytov Z (2016) How we can teach the mother tongue? Til alemi/World of Language Journal (Nov).

Baklovskaya O (2015) Multilingualism in education. In L Malykh, N Shutova, D Medvedeva (eds.), Cross-Culturally Oriented Technology of Multilingual Student's Training. Izhevsk: Publishing Center "Udmurt University".

Boden MA (1994) Dimensions of creativity. Cambridge, MA: MII Press.

Bogenbayeva A, Salamatova R, Sultaniyazova I, Sarsembayeva M, Orazbaeva F, Koyangaliyev Y (2017) The theoretical foundations of the formation of the future professionals' creative thinking. Man in India 97(10): 263-273.

Bruner JS (1979) On knowing: essays for the left hand. Cambridge, MA: Harvard University Press.

Carlile O, Jordan A (2012) Approaches to creativity: a guide for teachers. Open University Press. 
Edwards J (2012) Multilingualism: understanding linguistic diversity. London and New York: Continuum.

Grosjean F (1982) Life with two languages. Cambridge, MA: Harvard University Press.

Grosjean F, Li P (2013) The psycholinguistics of bilingualism. Malden, MA \& Oxford: Wiley-Blackwell.

King L (2018) The impact of multilingualism on global education and language learning. Cambridge Assessment English Perspectives.

King L, Carson L (2016) The multilingual city, vitality, conflict and change. Bristol: Multilingual Matters.

Kudryavtseva E (2015) Major provisions for education and development of NationalRussian bilinguals. In L Malykh, N Shutova, D Medvedeva (eds.), Multilingualism in Education. Izhevsk: Publishing Center "Udmurt University".

Lebedinsky SI, Herbik LF (2011) Methods of teaching Russian as a foreign language. Tutorial. Minsk.

Litosseliti L (2010) Research methods in linguistics. 1st Edition. Continuum International Publishing Group.

Little D (1991) Learner autonomy 1: definitions, issues, and problems. In L Malykh, N Shutova, D Medvedeva (eds.), Multilingualism in Education. Izhevsk: Publishing Center "Udmurt University".

Lopareva T (2015) Learning strategies in teaching multilingualism. In L Malykh, N Shutova, D Medvedeva (eds.), Multilingualism in Education. Izhevsk: Publishing Center "Udmurt University".

Marian V, Shook A (2012) The cognitive benefits of being bilingual. Cerebrum: the Dana forum on brain science: 13 .

Muhamediev D (2017) A trilingual system leads education to the heights. Retrieved from: https://qazaquni.kz/2017/11/30/78596.html. [Accessed 8 June 2021]

O'Malley JM, Chamot AU (1990) Learning strategies in second language acquisition. Cambridge: Cambridge University Press.

Orazaliyeva E (2019) A key to successful programs of the Kazakh language: student's needs identification. International Journal of Engineering, Applied and Management Sciences Paradigms (IJEAM) 54(5): 1-6.

Orazbayeva F (2019) Collected Works. Language space. V.3 Almaty: An-Arys.

Oxford R (1990) Language learning strategies: what every teacher should know. Boston, Massachusetts: Heinle \& Heinle.

Palinkašević R, Palov M (2014) The influence of bilingualism on cognition and third language acquisition. ELTA Journal 2(2): 82-93.

Rebecca L, Oxford (2003) Language learning styles and strategies: an overview. Oxford: GALA.

Roadmap for the development of trilingual education for 2015-2020 (2015) Kazakhstan: Kazakh American Free University.

Scarcella R, Oxford R (1992) The tapestry of language learning: the individual in the communicative classroom. Boston: Heinle \& Heinle.

Ubedh M (2016) Native speaker's strategy in teaching speaking. Thesis. Indonesia: State Islamic College Tulungagung.

Weinreich U (1974) Language in contact. The Hague: Mouton.

Wulff S, Ellis NC (2018) Usage-based approaches to second language acquisition. USA: University of Florida/University of Michigan. 